\title{
Vortex flows in acid solutions of lithium dihydrogen phosphate in a crystal growth unit
}

\author{
A.N.Iurchenko, K.N.Kulik, A.P.Voronov, G.N.Babenko \\ Institute for Single Crystals, STC "Institute for Single Crystals", \\ National Academy of Sciences of Ukraine, \\ 60 Lenin Ave., 61001 Kharkiv, Ukraine
}

Received November 28, 2014

\begin{abstract}
The characteristic properties of vortex flow induced by an external source under certain boundary conditions are established. Experimentally obtained are the data on the vortex size depending on the power of the source. The analytically established dependence is in agreement with the experimental data.

Keywords: lithium dihydrogen phosphate, crystal growth, vortex flow, stirring rate, Reynolds number, mass transfer.

Установлены характерные свойства вихревого течения, возбуждаемого внешним источником в определенных граничных условиях. Экспериментально получены данные о размерах вихря в зависимости от мощности источника. Зависимость, установленная аналитически, хорошо согласуется с экспериментальными данными.
\end{abstract}

Вихрові течії фосфорнокислих розчинів літій дигідрофосфату у ростовому апараті. А.М. Юрченко, К.М. Кулик, О.П. Воронов, Г.М. Бабенко.

Встановлено характерні властивості вихрової течії, яка збуджується зовнішнім джерелом у певних граничних умовах. Експериментально отримано дані про розміри вихору в залежності від потужності джерела. Залежність, встановлена аналітично, добре узгоджується із експериментальними даними.

\section{Introduction}

Lithium dihydrogen phosphate $\mathrm{LiH}_{2} \mathrm{PO}_{4}$ (LDP) plays a particular role in the group of KDP-type crystals. The latter are grown from aqueous solutions, whereas for LDP at a temperature above $20^{\circ} \mathrm{C}$ there is observed incongruent solubility [1-3]. Meanwhile it has been shown [3] that in the solutions, which contain excess of orthophosphoric acid, the crystals dissolve congruently. The solubility of LDP in phosphate solutions is rather high $(53$ wt. $\%$ in $100 \mathrm{~g}$ of the solution on the base of $20 \% \mathrm{H}_{3} \mathrm{PO}_{4}$ at $45^{\circ} \mathrm{C}$ [4]). Therefore, the viscosity of saturated phosphate LDP solutions by several times exceeds that of aqueous solutions [4]. Therefore, mass transfer in the process of crystal growth is essentially slower. As a rule, for raising the rate of mass transfer the solution contained in a growth unit is stirred. Optimum crystal growth conditions imply laminar flow of the solution in the vicinity of the growing surface. The criterion of the changeover from laminar to turbulent flow is the Reynolds number. The main part of the growth unit is a cylindrical vessel containing the solution in which the seed and a stirrer are placed. The intensity of the solution stirring is defined by the stirrer rotation velocity. This rotation creates vortex flow of the liquid, therefore, the aim of the present study is to clarify the main properties of vortex flow of LDP solution in a mixture of $\mathrm{H}_{2} \mathrm{O}$ and $\mathrm{H}_{3} \mathrm{PO}_{4}$ depending on the stirring intensity. 


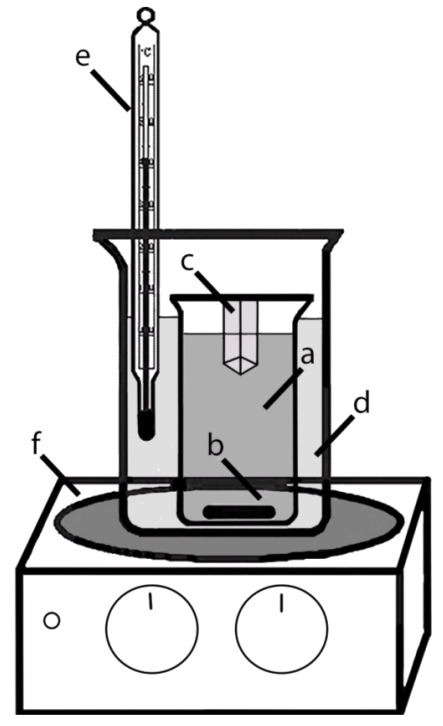

Fig. 1. Scheme of the experimental unit (a cylinder with the solution investigated; $\mathrm{b}$ magnetic anchor; c - a model seed; $d$ - water bath; e - thermometer; $\mathrm{f}$ - magnetic stirrer).

\section{Experimental}

Model experimental observations of the solution flows in the process of stirring were realized on the unit schematically shown in Fig. 1. The solution containing 52 wt. $\%$ of LDP in $20 \% \mathrm{H}_{3} \mathrm{PO}_{4}$ water solution was poured into a glass cylinder with a volume of $50 \mathrm{ml}$ and a radius of $15.6 \mathrm{~mm}$. Placed at the cylinder bottom was a magnetic anchor shaped as a rod $6 \mathrm{~mm}$ in diameter and $25 \mathrm{~mm}$ long. A model seed in the form of square rod with a side of $10 \mathrm{~mm}$ was placed in the upper part of the solution. As a tracer for observation of the

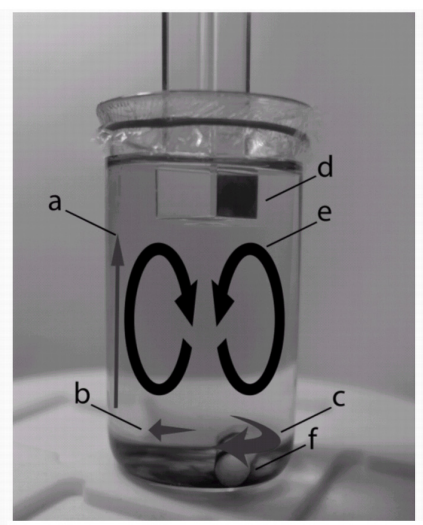

Fig. 2. Directions of the solution flow and path of the tracer particles (a - the vertical flow component $V_{z} ; \mathrm{b}-$ the radial flow component $V_{r} ; \mathrm{c}-$ the angular flow component $V_{\varphi} ; \mathrm{d}$ - the model seed of the crystal in the solution; e - general view of toroidal flow; f - magnetic anchor).

solution flow, there was used a suspension of fine-dispersed charcoal. The cylinder was placed into a thermostat (a water bath with a control thermometer). The thermostat was placed onto the magnetic stirrer with heating and control of the anchor rotation velocity. The solution flows at different temperatures and stirring velocity were filmed using high-speed camera at $100 \mathrm{fps}$. There were made series of measurements at the solution temperature of $25,30,35,45$ and $55^{\circ} \mathrm{C}$, the anchor rotation velocities being $190,249,308,367,425,484,543$ and $602 \mathrm{rpm}$.

Stirring of the solution in the cylinder gives rise to toroidal vortex flow rotating at a velocity which can be resolved into the

Table. Ratio of the vortex height $h$ to the solution level $L$ at different temperatures and stirring rates, calculated values of the Reynolds number and vertical component of the flow velocity.

\begin{tabular}{|c|c|c|c|c|c|c|c|c|c|c|c|c|c|c|c||}
\hline \multirow{2}{*}{$\begin{array}{c}W, \\
\min ^{-1}\end{array}$} & \multicolumn{3}{|c|}{25} & \multicolumn{3}{c|}{30} & \multicolumn{3}{c|}{35} & \multicolumn{3}{|c|}{45} & \multicolumn{3}{c||}{55} \\
\cline { 2 - 13 } & $h / L$ & $R e$ & $\begin{array}{c}V_{z}, \\
\mathrm{~cm} / \mathrm{s}\end{array}$ & $h / L$ & $R e$ & $\begin{array}{c}V_{z}, \\
\mathrm{~cm} / \mathrm{s}\end{array}$ & $h / L$ & $R e$ & $\begin{array}{c}\mathrm{V}_{\mathrm{z}}, \\
\mathrm{cm} / \mathrm{s}\end{array}$ & $h / L$ & $R e$ & $\begin{array}{c}V_{z}, \\
\mathrm{~cm} / \mathrm{s}\end{array}$ & $h / L$ & $R e$ & $\begin{array}{c}V_{z}, \\
\mathrm{~cm} / \mathrm{s}\end{array}$ \\
\hline 602 & 0.84 & 311 & 48 & 1.00 & 341 & 57 & 0.99 & 399 & 54 & 1.00 & 557 & 54 & 1.00 & 920 & 54 \\
543 & 0.83 & 281 & 43 & 0.96 & 308 & 49 & 0.99 & 360 & 48 & 1.00 & 502 & 49 & 1.00 & 830 & 49 \\
484 & 0.79 & 250 & 36 & 0.91 & 274 & 42 & 0.97 & 321 & 42 & 1.00 & 448 & 44 & 1.00 & 740 & 44 \\
425 & 0.75 & 220 & 20 & 0.88 & 241 & 36 & 0.96 & 282 & 37 & 0.98 & 393 & 38 & 1.00 & 650 & 38 \\
367 & 0.74 & 190 & 17 & 0.83 & 208 & 29 & 0.92 & 243 & 30 & 0.91 & 339 & 30 & 1.00 & 561 & 33 \\
308 & 0.73 & 159 & 14 & 0.80 & 175 & 24 & 0.89 & 204 & 25 & 0.87 & 285 & 24 & 1.00 & 471 & 28 \\
249 & 0.65 & 129 & 8 & 0.70 & 141 & 11 & 0.83 & 165 & 19 & 0.82 & 230 & 18 & 0.95 & 381 & 21 \\
190 & 0.52 & 98 & 5 & 0.55 & 108 & 7 & 0.72 & 126 & 12 & 0.76 & 176 & 13 & 0.92 & 291 & 16 \\
\hline
\end{tabular}




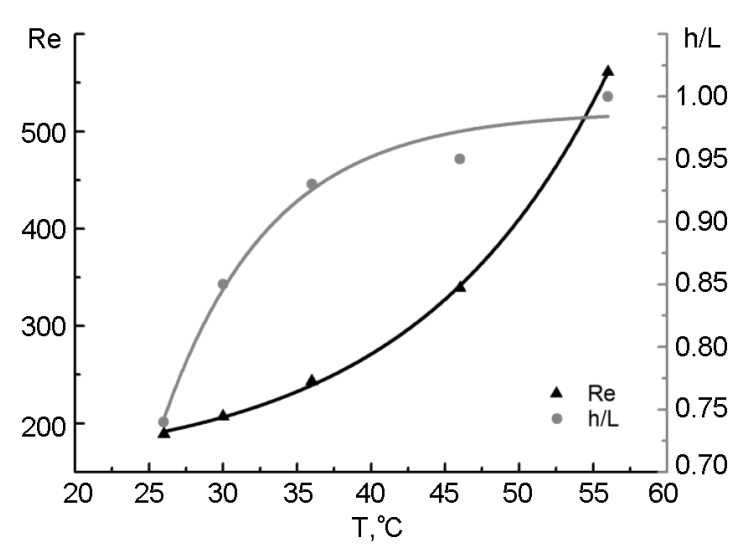

Fig. 3. Dependences of the ratio of the vortex height to the solution level $(h / L)$ and of the Reynolds number $(R e)$ on the temperature at 370 r.p.m. stirring rate.

following components: the angular $\left(V_{\varphi}\right)$; the radial $\left(V_{r}\right)$ and the vertical $\left(V_{z}\right)$ (Fig. 2).

The changes arising in the solution in the process of stirring were estimated using the ratio of the vortex height in the solution $h$ to the solution level $L: h / L$ as a criterion. Chosen as a criterion of the intensity of the solution stirring was the corresponding Reynolds number: $R e=V_{\varphi} R / v$; where $R$ is the cylinder radius; $v=\eta / \rho-$ the kinematic viscosity of the solution; $\eta-$ the solution viscosity; $\rho$ - the solution density; $V_{\varphi}=\omega R$ - the angular component of the solution flow velocity; $\omega-$ the angular velocity of the mixer anchor rotation.

The chosen criteria make it possible to use the results of the model experiment for a growth apparatus and to optimize the crystal growth conditions.

Table presents the values of the ratio of the vortex height $h$ in the solution to the solution level $L$ determined on the base of the video observations of the solution flows. The experiments were performed at different temperatures and stirring rates. The table also contains the calculated values of the Reynolds numbers.

As seen from Table, at the minimal stirring rate the vortex height increases as the temperature rises from $25^{\circ} \mathrm{C}$ to $55^{\circ} \mathrm{C}$ : the ratio $h / L$ changes from 0.52 to 0.92 . With the rise of the stirring rate the vortex height grows and reaches the limiting value $h / L=1$. Thereat, at the increase of the temperature less intense stirring is required.

Presented in Fig. 3 are the temperature dependences of the ratio $h / L$ and of the Reynolds number. As is seen, the growth of

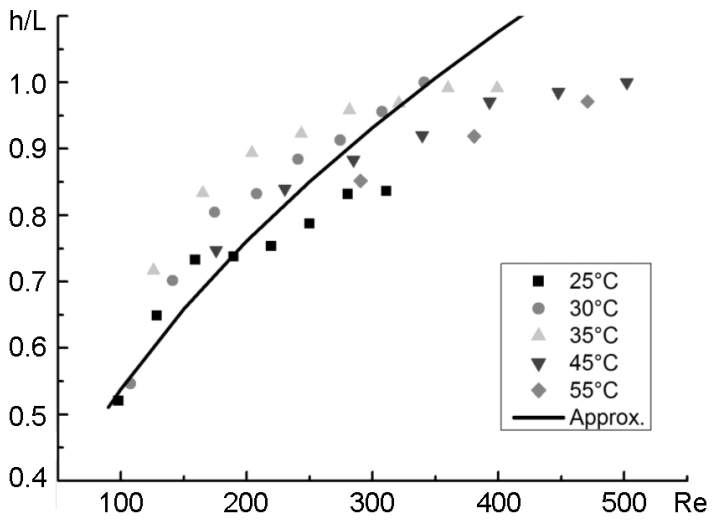

Fig. 4. Dependences of the ratio of the vortex height $(h)$ to the solution level $(L)$ on the Reynolds number $(R e)$ at different temperatures, and the approximating curve.

the temperature gives rise to particularly pronounced tendencies of the character of these dependences: the ratio $h / L$ tends to the limiting value and the Reynolds number increases. The dependence of the ratio $h / L$ on the Reynolds number has the form of the power function $h / L=A \cdot(R e)^{n}$. The obtained dependences of the vortex height ratio to the solution level on the Reynolds number at different temperatures are shown in Fig. 4.

\section{Discussion}

Consider the stationary state of viscous incompressible liquid over a rotating cylinder. The equations of incompressible viscous liquid in cylindrical coordinates have the form [5]:

$$
\begin{gathered}
V_{r} \frac{\partial V_{r}}{\partial r}+V_{z} \frac{\partial V_{r}}{\partial z}-\frac{V_{\varphi}^{2}}{r}= \\
=-\frac{1}{\rho} \frac{\partial P}{\partial r}+v\left(\frac{\partial^{2} V_{r}}{\partial r^{2}}+\frac{1}{r} \frac{\partial V_{r}}{\partial r}+\frac{\partial^{2} V_{r}}{\partial z^{2}}-\frac{V_{r}}{r^{2}}\right) ; \\
V_{r} \frac{\partial V_{\varphi}}{\partial r}+V_{z} \frac{\partial V_{\varphi}}{\partial z}+\frac{V_{r} V_{\varphi}}{r}= \\
=v\left(\frac{\partial^{2} V_{\varphi}}{\partial r^{2}}+\frac{1}{r} \frac{\partial V_{\varphi}}{\partial r}+\frac{\partial^{2} V_{\varphi}}{\partial z^{2}}-\frac{V_{\varphi}}{r^{2}}\right) ; \\
=-\frac{1}{\rho} \frac{\partial P}{\partial z}+v\left(\frac{\partial^{2} V_{z}}{\partial r^{2}}+\frac{1}{r} \frac{\partial V_{z}}{\partial r}+\frac{\partial^{2} V_{z}}{\partial z^{2}}\right) .
\end{gathered}
$$

Here $v$ is the liquid viscosity. These equations are to be complemented with the conditions of liquid incompressibility: 


$$
\frac{\partial V_{r}}{\partial r}+\frac{V_{r}}{r}+\frac{\partial V_{z}}{\partial z}=0 .
$$

Naturally, it is rather difficult to obtain the exact solution of this system of equations taking into account the boundary conditions. To find the numerical solution is much easier, however, further we intend to study the regularities of the flow propagation in vertical direction with changing stirring rate. Therefore, it seems expedient to restrict ourselves to simple qualitative estimations. Taking into account the structure of the vortex flow defined by the fluid incompressibility condition, one can estimate the ratio of the vertical component of the velocity to the radial component. As follows from the incompressibility condition,

$$
\frac{V_{r}}{R} \approx \frac{V_{z}}{h} \rightarrow \frac{V_{z}}{V_{r}} \approx \frac{h}{R} .
$$

Here $h$ is the characteristic vertical vortex size, $R$ - the characteristic radius of the cylinder. This relation shows that the vertical vortex size increases with the rise of the vertical velocity in comparison with the radial one. If one use the data on the velocity of the rotation of the cylinder bottom (stirrer) with the frequency $\omega$, it is natural to assume that for viscous liquid the characteristic velocity $I_{\varphi} \approx \omega R$ agrees with the rotation frequency of the source of motion. Using this relation, suppose that the nonlinear term in Eq. (2) is of the order of the viscous term:

$$
\frac{V_{r} V_{\varphi}}{R} \approx v \frac{\Delta V_{\varphi}}{R^{2}}
$$

and transform it as follows:

$$
\frac{V_{\varphi} R}{v} \approx \frac{\Delta V_{\varphi}}{V_{r}} .
$$

where $V_{\varphi} \approx \omega R$ is the characteristic rotation velocity, $\Delta V_{\varphi}$, the characteristic change of the rotation velocity. Then we obtain:

$$
R e \approx \frac{\Delta V_{\varphi}}{V_{r}} .
$$

In this expression, the Reynolds number $R e=V_{\varphi} R / \nu$ is determined from the angular characteristic rotation velocity and depends on the rotation frequency. For estimation of $\Delta V_{\varphi}$ one can compare the last two viscous contributions in Eq. (2), assuming viscous components to be of the same order:

$$
\frac{\Delta V_{\varphi}}{h^{2}} \approx \frac{V_{\varphi}}{R^{2}}
$$

Thus,

$$
\Delta V_{\varphi} \approx \frac{h^{2}}{R^{2}} V_{\varphi}
$$

Finally, on the premise that $V_{\varphi} \approx V_{r}$ we obtain:

$$
\Delta V_{\varphi} \approx \frac{h^{2}}{R^{2}} V_{r}
$$

The substitution of the obtained expression in Eq. (6) yields the following relation:

$$
\frac{h^{2}}{R^{2}} \approx R e \rightarrow \frac{h}{R} \approx \sqrt{R e} \rightarrow \frac{h}{L} \approx \frac{R}{L} \cdot \sqrt{R e} \text { (7) }
$$

Therefore, the rise of the characteristic vertical vortex size and, consequently, of the active flow zone is proportional to the square root of the Reynolds number. The latter is estimated from the angular rotation velocity. The constant multiplier in Eq. (7) found from the experimental data has the following form:

$$
\frac{h}{L} \approx \frac{\pi}{16.9} \cdot \frac{R}{L} \cdot \sqrt{\mathrm{Re}} .
$$

This relation agrees with the experimental data. Strictly speaking, it should be noted that it is not applicable in the region of $h / L \approx 1$, due to an essential influence of free liquid boundary in this region, and an intricate shape of the solid immersed in the liquid. Such factors were present in the experiment, but were not taken into account in the theoretical estimations.

The graph presented in Fig. 4 has the characteristic region $0.95 \leq h / L \leq 1.0$ corresponding to the values of the Reynolds number $300 \leq R e \leq 350$. Here the proportional rise of the characteristic vertical vortex size and laminar flow of the liquid in the flow are disturbed. That seems to be caused by the above-mentioned essential influence of the free liquid boundary. Presented in Table are the maximum values of the vertical component of the liquid flow velocity in the vortex $\left(V_{z}\right)$ depending on the Reynolds number. The values of the vertical flow velocity close to $30 \mathrm{~cm} / \mathrm{s}$ point to the changeover to the kinetic crystal growth regime [6]. As seen from the table, such characteristic vertical velocities are achieved at the Reynolds numbers $250 \leq R e \leq 350$. 
The Reynolds number is one of similarity criteria, which allow estimating the stirring conditions in a real crystal growth apparatus. Assume that the diameter of the cylindrical growth vessel is $16 \mathrm{~cm}$ and the solution level $L$ is also $16 \mathrm{~cm}$, then at the required growth temperature $40^{\circ} \mathrm{C}$, $\omega$ is about $30 \mathrm{rpm}$. Thereat, the magnetic anchor must have a diameter of $15 \mathrm{~mm}$ and a length of $60 \mathrm{~mm}$. These values are reasonable for the process of crystal growth.

\section{Conclusion}

The performed study of the conditions of stirring of acid solution of lithium dihydrogen phosphate in a cylindrical vessel shows centrifugal stirring of the solution gives rise to the appearance of a toroidal vortex which characteristic vertical size $(h / L)$ depends on the stirring velocity and the solution temperature.

The rise of the characteristic vertical vortex size is found to be proportional to the square root of the Reynolds number $\frac{h}{L} \approx \frac{\pi}{16.9} \cdot \frac{R}{L} \cdot \sqrt{\operatorname{Re}}$.

The obtained results are compared with the conditions of stirring in a real growth apparatus. Effective mass transfer in the solution is provided by the eigenvalue of the criterion $h / L \leq 0.95$ and the Reynolds numbers $250 \leq R e \leq 350$.

\section{References}

1. M.Catti, G.Ivaldi, Zeitschrift fur Kristallographie, 146, 215 (1977).

2. L.V.Soboleva, I.L.Smolsky, Crystallogr. Reports, 42, 700 (1997).

3. A.B.Rollet, R.Zaufenburger, Bull.Soc.Chim. France, 5, 146 (1934).

4. A.N.Iurchenko et al., Functional Materials, 21, 324 (2014)

5. L.D.Landau, E.M.Livshits, Hydrodynamics, Science Publ., Moscow (1986) [in Russian].

6. V.N.Portnov, E.V.Chuprunov, Vozniknovenije i Rost Kristallov, Fizmatlit, Moscow (2006) [in Russian]. 